\title{
Determination of Molecular Weight of Soluble Ovalbumin Aggregates during Heat Denaturation Using Low Angle Laser Light Scattering Technique
}

\author{
Akio Kato, Yasuo Nagase, Naotoshi Matsudomi \\ and Kunihiko KoBAYASHI \\ Department of Agricultural Chemistry, Faculty of Agriculture, \\ Yamaguchi University, Yamaguchi 753, Japan
}

Received January 10, 1983

\begin{abstract}
The apparent molecular weights of soluble ovalbumin aggregates occurring under various heating conditions were determined by using the low angle laser light scattering technique in combination with high performance liquid chromatography. The soluble ovalbumin aggregates were rapidly formed near the melting point $\left(76^{\circ} \mathrm{C}\right)$ for thermal denaturation. The apparent molecular weight of the soluble ovalbumin aggregates increased with the heating temperature from $4,000,000$ at $76^{\circ} \mathrm{C}$ to $35,000,000$ at $100^{\circ} \mathrm{C}$. It also increased in proportion to the protein concentration, ionic strength and standing time. In the presence of sodium dodecyl sulfate, the soluble ovalbumin aggregates dissociated into lower molecular weight fractions, mainly monomeric and oligomeric. On the other hand, the molecular weight of the soluble ovalbumin aggregates did not change in the presence of mercaptoethanol or $N$-ethylmaleimide. The soluble ovalbumin aggregates were formed in proportion to an increase in the surface hydrophobicity of heatdenatured ovalbumins. From these results, it was suggested that the soluble ovalbumin aggregates were formed mainly by hydrophobic interaction.
\end{abstract}

The mechanism of the structure formation of globular proteins such as gelation during heat denaturation is poorly understood, although the process of heat-denatured aggregation of ovalbumin has been extensively investigated. ${ }^{1 \sim 3)}$ Since insoluble aggregates occur during heat denaturation, turbidity measurement is usually used to follow proteinprotein interaction. This is one of the reasons why the mechanism of protein-protein interaction is poorly understood during heat denaturation. Nakamura et al. have reported that a main factor contributing to the heat-induced aggregation of ovalbumin was electrostatic force." On the other hand, Shimada and Matsushita have reported that the first step of ovalbumin coagulation involved the formation of disulfide bonds and the exposure of hydrophobic groups, and then during further heating ovalbumin was polymerized by intermolecular sulfhydryl-disulhydryl exchange to form protein network structure. ${ }^{2)}$ They used turbidity measurement to follow the formation of ovalbumin aggregates.

In order to elucidate further the mechanism of aggregation of ovalbumin, it is important to distinguish between the first step (soluble aggregation) and the second step (insoluble aggregation). Ovalbumin forms soluble aggregates according to the heat condition used. Ma and Holme have reported the existence of high molecular weight soluble aggregates in egg albumin heated in boiling water for $3 \mathrm{~min}$ at $\mathrm{pH}$ 8.0. ${ }^{3)} \mathrm{We}$ also found the soluble aggregates of ovalbumin without any coagulum by heating at $85^{\circ} \mathrm{C}$ in $0.01 \mathrm{M}$ phosphate buffer, $\mathrm{pH} \mathrm{7.4.{ } ^ { 4 } )}$ To investigate the formation process of soluble ovalbumin aggregates, it is desirable to estimate rapidly and exactly the molecular weight of the aggregates. Recently, Takagi $e t$ al. have developed the low angle laser light scattering technique in combination with high performance liquid chromatography. ${ }^{5}{ }^{5}$ This technique seems to be promising to determine 
the molecular weight of such giant molecules as soluble aggregates of ovalbumin. This paper describes the properties of soluble aggregates of ovalbumin and the mechanism of soluble aggregation during heat denaturation using this technique.

\section{MATERIALS AND METHODS}

Ovalbumin was prepared by the sodium sulfate method from fresh chicken egg white and recrystallized five times. Heat denaturation of ovalbumin was carried out as follows: $5 \mathrm{ml}$ of $0.1 \%$ ovalbumin solutions in $1 / 15 \mathrm{M}$ phosphate buffer, $\mathrm{pH} 7.4$, containing $0.1 \mathrm{M} \mathrm{NaCl}$ was heated in an incubator at the rate of $2^{\circ} \mathrm{C} / \mathrm{min}$ from $30^{\circ} \mathrm{C}$ to a given temperature, and then immediately cooled to room temperature. The heat-denatured ovalbumin thus obtained was used in the experiments. Under these conditions, no coagulum occurred during heating.

Gel filtration of heat-denatured ovalbumin was carried out by high performance liquid chromatography (HLC805, Toyo Soda Co.) on a TSK Gel G3000SW column (Toyo Soda Co.; $0.75 \times 60 \mathrm{~cm}$ ). $0.1 \mathrm{ml}$ of $0.1 \%$ ovalbumin solutions in $1 / 15 \mathrm{M}$ phosphate buffer, $\mathrm{pH} 7.4$, containing $0.1 \mathrm{M} \mathrm{NaCl}$ was applied on a column at a flow rate of $0.65 \mathrm{ml} / \mathrm{min}$. A variable length UV detector (SF 770, Toyo Soda Co.) ws used to monitor the effluent at $280 \mathrm{~nm}$.

Light scattering was measured with a low angle (He-NE, $633 \mathrm{~nm}$ ) light scattering photometer (LS-8, Toyo Soda Co.) with a flow-through cell of an internal volume of 30 microliter. Output of the light scattering photometer was recorded on a dual-pen recorder together with that of a precision differential refractometer (RI-8, Toyo Soda Co.). One $\mathrm{ml}$ of $0.1 \%$ ovalbumin solutions in $1 / 15 \mathrm{M}$ phosphate buffer, $\mathrm{pH} 7.4$, containing $0.1 \mathrm{M} \mathrm{NaCl}$ was applied to the light scattering photometer via a TSK gel G3000SW column at a flow rate of $0.7 \mathrm{ml} / \mathrm{min}$, and then to a differential refractometer. All measurements were carried out at $25 \pm 2^{\circ} \mathrm{C}$. The gain of light scattering (abbreviated as LS) peak was adjusted according to the samples, while that of refractive index (abbreviated as RI) peak was set to 256. The LS gain of standard protein was set to 32 and that of heat-denatured ovalbumins was set to 1 . Molecular weight of ovalbumin aggregates was estimated from the ratio of the output of the scattering photometer, (Output $)_{\mathrm{LS}}$, to that of the refractometer, (Output) $)_{\mathrm{RI}}$, by the method of Takagi ${ }^{5}$ in a slightly modified form. The ratio of (Output) $)_{\mathrm{LS}}$ to (Output) $\mathrm{RI}_{\mathrm{RI}}$ can be proportional to the molecular weight of sample proteins, as follows:

$$
\frac{(\text { Output })_{\mathrm{LS}}}{(\text { Output })_{\mathrm{RI}}}=K \cdot \frac{(\mathrm{d} n / \mathrm{d} c)_{\text {std }}}{(\mathrm{d} n / \mathrm{d} c)_{\mathrm{sam}}} \cdot M w
$$

where $K, \mathrm{~d} n / \mathrm{d} c, M w$, std and sam are instrument constant, the refractive index increment of protein at $633 \mathrm{~nm}$, the molecular weight of protein, standard and sample protein, respectively. Since the output of the refractometer linearly increases with sample concentration, Eq. (1) is represented as follows:

$$
\begin{aligned}
M w= & \frac{(\text { Output })_{\mathrm{LS}} \text { of sample }}{(\text { Output })_{\mathrm{RI}} \text { of sample }} \\
& \frac{1}{K} \cdot \frac{(\text { Output })_{\mathrm{RI}} \text { of standard }}{(\text { Output })_{\mathrm{RI}} \text { of sample }} \cdot \frac{C_{\text {sam }}}{C_{\text {std }}}
\end{aligned}
$$

where $C$ is the concentration of sample and standard protein. The constant, $K$, can be determined from measurements of known molecular weight standard proteins as follows:

$$
K=\frac{(\text { Output })_{\mathrm{LS}} \text { of standard }}{(\text { Output })_{\mathrm{RI}} \text { of standard }} \cdot \frac{1}{M w \text { of standard }}
$$

Bovine serum albumin (Sigma Chemical Co.) was used as a standard protein.

Mercaptoethanol treatment of ovalbumin was carried out by the addition of $0.1 \%$ mercaptoethanol into $0.1 \%$ ovalbumin solution in $1 / 15 \mathrm{M}$ phosphate buffer, $\mathrm{pH} 7.4$, containing $0.1 \mathrm{M} \mathrm{NaCl}$. $N$-Ethylmaleimide treatment of ovalbumin was carried out by the addition of $0.01 \% \mathrm{~N}$ ethylmaleimide into $0.1 \%$ ovalbumin solution in $1 / 15 \mathrm{M}$ phosphate buffer, $\mathrm{pH} 7.4$, containing $0.1 \mathrm{M} \mathrm{NaCl}$. SH- and SS-groups were determined by the method of Beveridge $e t$ $a l^{6}{ }^{6}$ during the heat denaturation of ovalbumin.

The surface hydrophobicity of heat-denatured ovalbumin was determined by using the method described previously. ${ }^{7)}$ Ten microliters of ethanolic solutions of cisparinaric acid, $3.6 \times 10^{-3} \mathrm{M}$, were added to $2 \mathrm{ml}$ of the protein solution. The mixtures were excited at $325 \mathrm{~nm}$ and the relative fluore scence intensity was measured at $420 \mathrm{~nm}$. The initial slope $\left(S_{0}\right)$, fluorescence intensity $/ \%$ protein, was calculated from the fluorescence intensity $v s$. protein concentration.

\section{RESULTS AND DISCUSSION}

Figure 1 shows the high performance liquid chromatograms of heat-denatured ovalbumins detected by a UV monitor at $280 \mathrm{~nm}$. The peak of native ovalbumin eluted at an elution time of 29 min. During heat denaturation, the peak of highly-aggregated ovalbumin eluted at an elution time of $17 \mathrm{~min}$, corresponding to the void volume, without oligomeric ovalbumin peaks. The peak of ovalbumin aggregates increased with the heating temperature. A remarkable increase in ovalbumin aggregates was apparent near the melting point $\left(76^{\circ} \mathrm{C}\right)$ for thermal denaturation. ${ }^{8}$ )

The molecualr weight of ovalbumin aggregates was determined by using the low angle laser light scattering technique in com- 


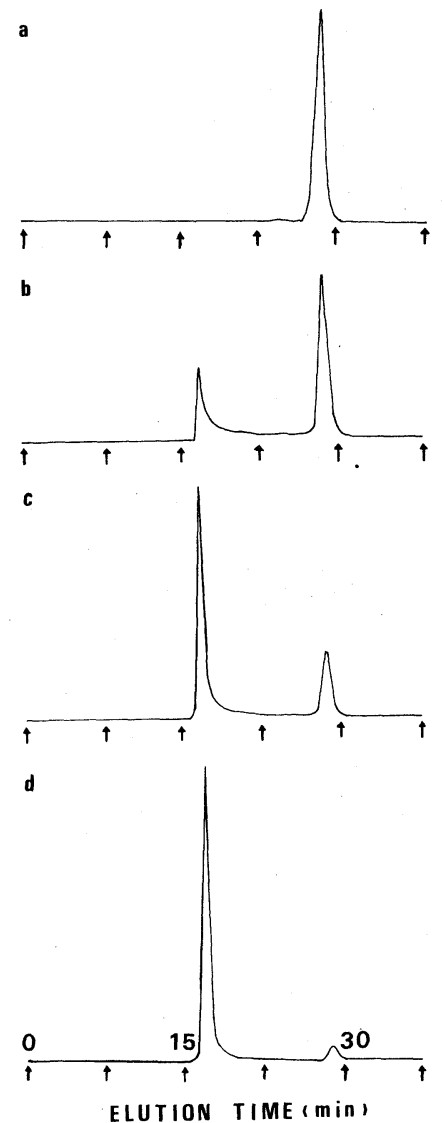

FIG. 1. High Performance Liquid Chromatograms of Heat-denatured Ovalbumins Detected by a UV Spectroflow Monitor.

a, native ovalbumin; b, ovalbumin heated to $73^{\circ} \mathrm{C}$; $\mathrm{c}$, ovalbumin heated to $76^{\circ} \mathrm{C}$; d, ovalbumin heated to $80^{\circ} \mathrm{C}$. $0.1 \%$ ovalbumin solutions in $1 / 15 \mathrm{~m}$ phosphate buffer, $\mathrm{pH}$ 7.4 , containing $0.1 \mathrm{M} \mathrm{NaCl}$ were heated at the rate of $2^{\circ} \mathrm{C} /$ min from $20^{\circ} \mathrm{C}$ to a given temperature and then immediately cooled to $20^{\circ} \mathrm{C}$.

bination with high performance liquid chromatography. It should be called the apparent weight average molecular weight (abbreviated below as the apparent molecular weight), because ovalbumin aggregates elute at the void volume and the molecular weights are determined by light scattering technique. Figure 2 shows the high performance liquid chromatograms of heat-denatured ovalbumins detected by light scattering and refractive index. The gain setting of the LS peak for native ovalbumin (A) is 32 times that for denatured

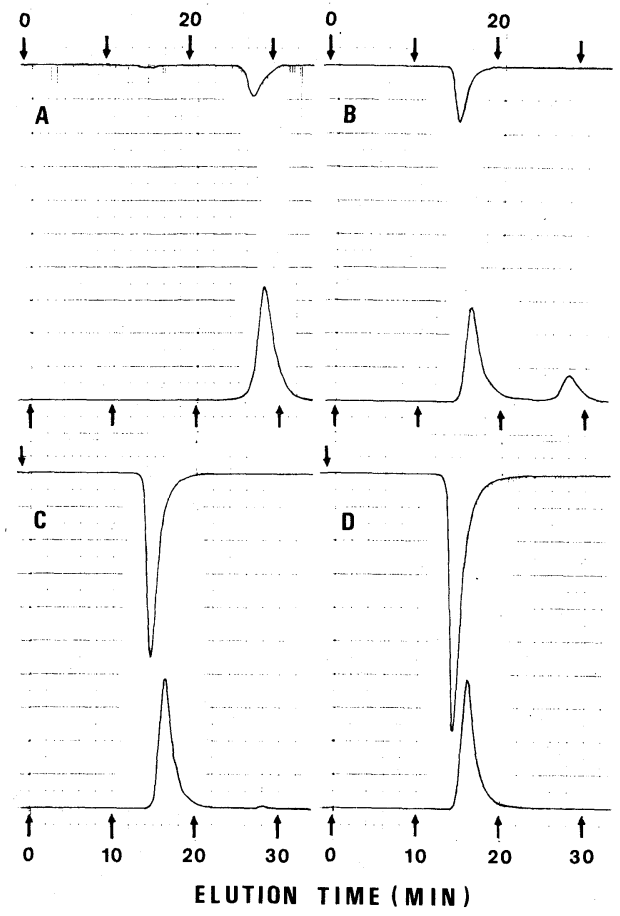

FIG. 2. High Performance Liquid Chromatograms of Heat-denatured Ovalbumin Detected by Light Scattering (Top) and Refractive Index (Bottom).

A, native ovalbumin; $\mathrm{B}$, ovalbumin heated to $78^{\circ} \mathrm{C}$; $\mathrm{C}$, ovalbumin heated to $82^{\circ} \mathrm{C}$; D, ovalbumin heated to $90^{\circ} \mathrm{C}$. The heating condition of ovalbumin was the same as for Fig. 1. Gain setting for A: LS, 32; RI, 256. Gain setting for B, C and D: LS, 1; RI, 256.

ovalbumin (B, C and D), because the molecular weight $(44,000)$ of ovalbumin is too small to detect the LS peak by using the same gain as denatured ovalbumin. The LS peak of ovalbumin aggregates remarkably increased with the heating temperature, although the RI peak of ovalbumin aggregates was of the same height. This suggests the progress of ovalbumin aggregation during heating. The apparent molecular weight of ovalbumin aggregates was determined from the ratio of the peak height of LS to that of RI, as described in Methods.

As shown in Fig. 3, the apparent molecular weight of ovalbumin aggregates increased with the heating temperature in the range of $4,000,000$ at $76^{\circ} \mathrm{C}$ to $35,000,000$ at $100^{\circ} \mathrm{C}$. Even at $100^{\circ} \mathrm{C}$, no coagulum occurred under 
the heating condition used. Thus, the apparent molecular weight of soluble ovalbumin aggregates seems to increase gradually with the heating temperature.

Figure 4 shows the slow progress of soluble aggregation on standing heat-denatured ovalbumin at room temperature. The apparent molecular weight of ovalbumin aggregates increased about three times after $24 \mathrm{hr}$. This result suggests the existence of a gradual aggregation process of heat-denatured ovalbumin.

Figure 5 shows the aggregation dependence of heat-denatured ovalbumin on concentration. The apparent molecular weight of ovalbumin aggregates increased with concentration. A slight turbidity developed at a concentration higher than $0.25 \%(\mathrm{w} / \mathrm{v})$, suggesting that insoluble aggregates were formed.

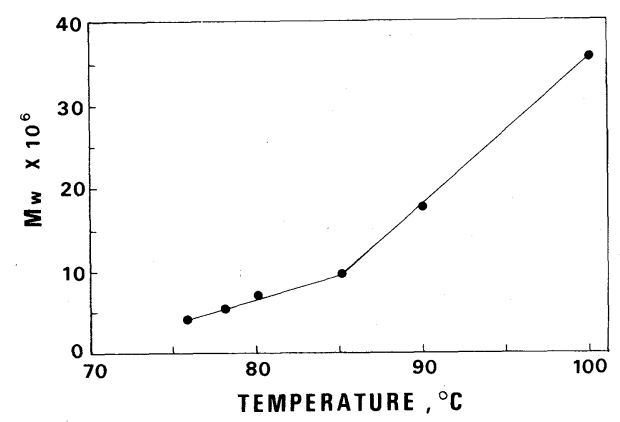

FIG. 3. Effect of Heating Temperature on the Formation of Ovalbumin Aggregates.

The heating condition of ovalbumin was the same as Fig. 1.

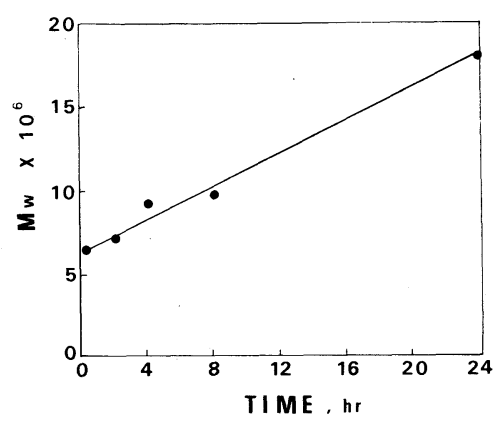

FIG. 4. Effect of Standing Time on the Formation of Ovalbumin Aggregates.

Ovalbumin aggregates were formed by heating to $80^{\circ} \mathrm{C}$ in the same condition as for Fig. 1, and were then stood for a given time at room temperature.
Figure 6 shows the dependence of salt concentration on the aggregation of heatdenatured ovalbumin. The molecular weight increased with $\mathrm{NaCl}$ molarity. This result suggests that the shielding of electrostatic groups in ovalbumin may accelerate the aggregation.

It is interesting that the apparent maximum molecular weight of soluble ovalbumin aggregates is about $35,000,000$ as shown in Figs. 3, 5 and 6 . This may mean that the limiting molecular weight of soluble ovalbumin aggregates is $35,000,000$. Thus, the formation of soluble ovalbumin aggregates has been shown to depend on various environmental factors including heating temperature, protein concentration, ionic strength and standing time after heating.

It has been proposed that the insoluble

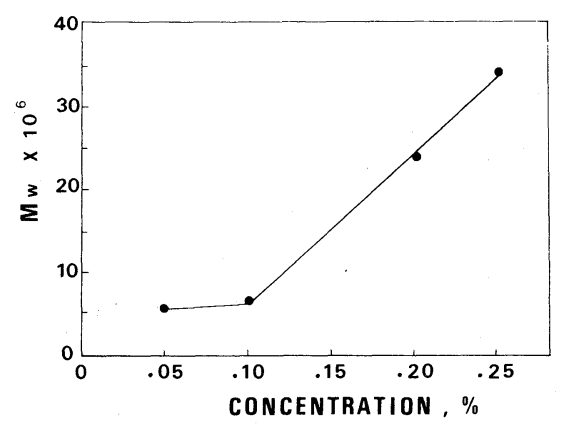

FIG. 5. Effect of Protein Concentration on the Formation of Ovalbumin Aggregates.

Ovalbumin aggregates were formed by heating to $80^{\circ} \mathrm{C}$ in the same condition as for Fig. 1.

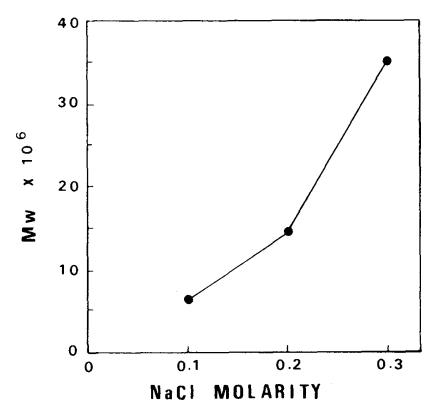

Fig. 6. Effect of $\mathrm{NaCl}$ Molarity on the Formation of Ovalbumin Aggregates.

Ovalbumin aggregates were formed by heating to $80^{\circ} \mathrm{C}$ in the same condition as for Fig. 1. 


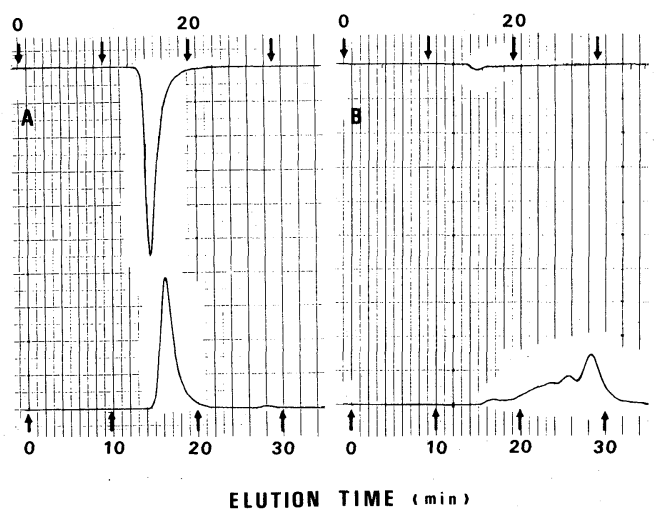

FIG. 7. Effect of Sodium Dodecyl Sulfate on the High Performance Liquid Chromatogram of Ovalbumin Aggregates Detected by Light Scattering (Top) and Refractive Index (Bottom).

A, ovalbumin aggregate heated to $82^{\circ} \mathrm{C} ; \mathrm{B}, 0.1 \%$ SDS were added to the ovalbumin aggregate heated to $82^{\circ} \mathrm{C}$. The heating condition of ovalbumin was the same as for Fig. 1. Gain setting: LS, 1; RI, 256.

aggregates, gel or coagulum, of ovalbumin are formed by all types of protein interaction, including sulfhydryl groups, electrostatic sites, hydrophobic and hydrogen bonds. ${ }^{1 \sim 3)}$ The roles of these interactions on the formation of soluble ovalbumin aggregation were investigated by the low angle laser light scattering technique. Figure 7 shows the effect of sodium dodecyl sulfate on the high performance liquid chromatograms of heat-denatured ovalbumin detected by light scattering and refractive index. The peak of ovalbumin aggregates eluted at the void volume mostly diminished in the presence of $0.1 \%$ sodium dodecyl sulfate, and the peaks corresponding to monomeric and oligomeric ovalbumins newly emerged in broad forms. This result suggests the importance of hydrophobic interaction for the formation of soluble ovalbumin aggregates. This is also supported from the result that the soluble ovalbumin aggregates increased in proportion to the increase in surface hydrophobicity of ovalbumin during heat denaturation, as shown in Fig. 8.

The effect of sulfhydryl groups on ovalbumin aggregation is shown in Table I. The soluble aggregates were likewise formed by

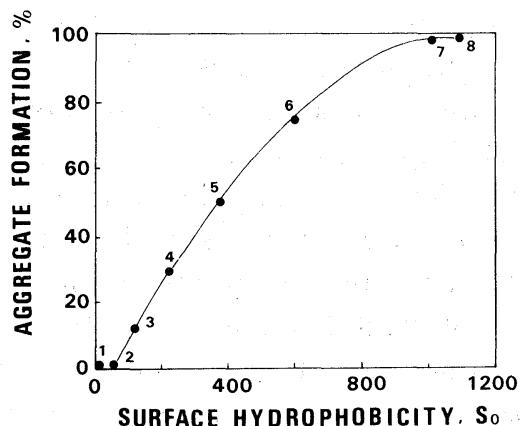

FIG. 8. Relationship between Surface Hydrophobicity and Aggregation Formation of Heat-denatured Ovalbumin.

1, native ovalbumin; 2 , ovalbumin heated to $70^{\circ} \mathrm{C} ; 3$, ovalbumin heated to $72^{\circ} \mathrm{C} ; 4$, ovalbumin heated to $73^{\circ} \mathrm{C}$; 5 , ovalbumin heated to $74^{\circ} \mathrm{C} ; 6$, ovalbumin heated to $76^{\circ} \mathrm{C}$; 7 , ovalbumin heated to $78^{\circ} \mathrm{C} ; 8$, ovalbumin heated to $80^{\circ} \mathrm{C}$. The formation of ovalbumin aggregates was measured from high performance liquid chromatograms.

Table I. Molecular Weight of Ovalbumin Aggregates in the Presence of

MerCaPtoethanol aND $N$-ETHYLMALEImide

Ovalbumin aggregates were formed by heating at $80^{\circ} \mathrm{C}$.

\begin{tabular}{lc}
\hline \multicolumn{1}{c}{ Ovalbumin aggregate } & Molecular weight \\
\hline Control & $6.2 \times 10^{6}$ \\
Mercaptoethanol-treated & $6.2 \times 10^{6}$ \\
$N$-Ethylmaleimide-treated & $8.8 \times 10^{6}$ \\
\hline
\end{tabular}

Table II. Changes In SH and SS Contents of Heat-denatured Ovalbumin

\begin{tabular}{|c|c|c|}
\hline \multirow{2}{*}{ Ovalbumin } & \multicolumn{2}{|c|}{$\begin{array}{c}\text { Content } \\
\text { (mol/mol protein) }\end{array}$} \\
\hline & $\mathrm{SH}$ & SS \\
\hline Native & 4.0 & 1.1 \\
\hline Heated at $65^{\circ} \mathrm{C}$ & 3.9 & 1.3 \\
\hline Heated at $70^{\circ} \mathrm{C}$ & 3.9 & 1.0 \\
\hline Heated at $75^{\circ} \mathrm{C}$ & 3.9 & 1.2 \\
\hline Heated at $80^{\circ} \mathrm{C}$ & 3.9 & 1.1 \\
\hline Heated at $85^{\circ} \mathrm{C}$ & 3.9 & 1.2 \\
\hline
\end{tabular}

heating ovalbumin solutions in the presence of mercaptoethanol or $N$-ethylmaleimide and significant changes in the molecular weight of ovalbumin aggregates were not observed, although that slightly increased in ovalbumin 
aggregates in the presence of $N$-ethylmaleimide. This result suggests that sulfhydryl groups are not responsible for the formation of soluble aggregates of heat-denatured ovalbumin. This is compatible with the result that no significant changes in the $\mathrm{SH}$ and SS contents are observed during the heat denaturation of ovalbumin, as shown in Table II.

From these results, the soluble ovalbumin aggregates seem to be formed mainly by hydrophobic interaction due to a marked increase in surface hydrophobicity of ovalbumin during heat denaturation.

Thus, low angle laser light scattering in combination with high performance liquid chromatography seems to be a very useful tool to observe the process of the formation of protein aggregates during thermal denaturation.
Acknowledgments. The authors are grateful to Toyo Soda Co. for making the low angle light scattering study possible. We are also grateful to Tetsuya Fujishige for his skillful technical assistance.

\section{REFERENCES}

1) R. Nakamura, H. Sugiyama and Y. Sato, Agric. Biol. Chem., 42, 819 (1978).

2) K. Shimada and S. Matsushita, J. Agric. Food Chem., 28, 409 (1980).

3) C. Y. Ma and J. Holme, J. Food Sci., 47, 1454 (1982).

4) A. Kato and S. Nakai, Biochim. Biophys. Acta, 624, 13 (1980).

5) T. Takagi, J. Biochem., 89, 363 (1981).

6) T. Beveridge, S. J. Toma and S. Nakai, J. Food Sci., 39, 49 (1974).

7) A. Kato, N. Tsutsui, N. Matsudomi, K. Kobayashi and S. Nakai, Agric. Biol. Chem., 45, 2755 (1981).

8) E. Stellwagen and H. Wilgus, Nature, 275, 342 (1978). 